\title{
Value at Risk for Gold Spot Based on Quantile-GARCH Model
}

\author{
Li Li ${ }^{1,2,3}$, Lei Xiao",* \\ ${ }^{1}$ Yunnan Association for Promotion of Trans-Asian Financial Cooperation and Development, \\ Kunming 650092, China \\ ${ }^{2}$ Pan-Asia Business School, Yunnan Normal University, Kunming 650092, China \\ ${ }^{3}$ Champion Property \& Casualty Insurance Co., Ltd., Kunming 650228, China \\ ${ }^{4}$ School of MARXISM Studies, Kunming University, Kunming 650214, China
}

\section{基于 Quantile-GARCH 模型的黄金现货风险价值 度量 \\ 李丽 ${ }^{1,2,3}$, 肖否 $4, *$ \\ ${ }^{1}$ 云南省泛亚金融合作发展促进会, 昆明 650092, 中国 \\ ${ }^{2}$ 云南师范大学泛亚商学院, 昆明 650092, 中国 \\ ${ }^{3}$ 诚泰财产保险股份有限公司, 昆明 650228, 中国 \\ ${ }^{4}$ 昆明学院马克思主义学院, 昆明 650043, 中国}

\begin{abstract}
With the rapid development of gold spot market, the value at risk of gold spot took attention of market participants. Spot gold trading time series data show the peak, fat tail and clustering properties. In this paper, a new kind of Quantile-GARCH Model was introduced and used to measure the value at risk of spot gold AU9999. The results showed that such Quantile-GARCH Model could grasp the gold spot market's value at risk under the $99 \%$ confidence level.
\end{abstract}

Keywords: Gold Spot; Quantile- GARCH model; Value at Risk

摘要
黄金现货市场的迅速发展引起了市场参与者
对黄金现货风险价值的关注。黄金现货交易的
时间序列数据展现出尖峰、厚尾、聚集的特性。
本文运用一类新型的 Quantile-GARCH 模型对

*Corresponding author: 43063010@qq.com
我国黄金现货 AU9999 的数据进行风险价值实 证分析。结果表明: 基于这类 Quantile-GARCH 模型在 $99 \%$ 的置信水平下能够较好地刻画黄 金现货市场的风险价值。

关键词：黄金现货; Quantile-GARCH; 风险 价值

\section{Introduction}

Gold is an internationally recognized hard currency and a society symbol for personal wealth, while gold reserves also affect the stability of a country's financial markets. With the outbreak of the financial crisis, international economic risk and financial risk gradually appear, Gold hedging function attracts the majority of investors' attention, a lot of money thus crowd in the gold market. China has launched gold spot in the Shanghai Spot Exchange from October 2002, which means that China's gold market began the process of marketization, gold investment gradually began to ordinary investors. The healthy development of gold spot market is beneficial for gold 


\section{Risk Analysis and Crisis Response in Big Data Era (RAC-16)}

production and consumption of financial institutions and enterprises to avoid price fluctuations and risk hedging. Therefore, it is very important to explore the amount of information containing gold spot price fluctuations with Chinese gold spot as the research object.

From the mathematical perspective considered in this paper, risk measure is a procedure for modeling a loss distribution. In the past two decades, many models have been widely used to study the return of assets, risk measurement and option pricing. The core of risk management is to identify and measure risks, most scholars opt Volatility forecasting GARCH model to estimate market risk.

GARCH (1986) [1] model is developed on the basis of the ARCH model (1982). Depend on different variance equation assumptions, forming a model form GARCH, EGARCH, GARCH-M and TARCH different types. As a major parameter prediction algorithm for VaR analysis, GARCH model occupies an important position in the field of financial risk management practice. Laurent and Peters (2002) [2], and other scholars use different $\mathrm{ARCH}$ models for financial risk management [3].

In recent years, more and more researches found the financial time series, including gold spot, have leptokurtic and asymmetric features. In above mentioned classical models, the marginal distribution of the underlying assets is assumed to be normal. However, many empirical studies suggest that the distribution is skewed and has a higher peak and heavier tails than those of the normal distribution. To grasp the above features of financial time series, Jiang and Deng (2000) proposed two new quantile-based probabilistic models. The advantage of the probabilistic model is that it is able to accurately describe the leptokurtic and fat tails features of financial data. In 2004, Jiang and Deng also presented Quantile-GARCH model which have been successfully applied in the empirical studies for German stock market and electricity price market in US (see [4]). They called it Quantile-GARCH model to show its close relationship with new quantile distribution. In this paper, we will detect weather it fit the gold spot price suitably.

The rest of this paper is organized in the following way. In the section 2, we will firstly introduce the two classes of quantile-based probabilistic models proposed by Jiang. In the section 3, we review the fundamental result of Quantile-GARCH model and underline the model's advantages for risk management. In particular, we fit the log returns of Gold Spot price by Quantile GARCH $(1,1)$ model. Finally, in the last section, we present a summary of the full text.

\section{Two Classes quantile-based Distributions}

\subsection{Quantile Function}

In probability theory, quantile function is an important tool for describing a random variable. If $F$ is a probability distribution function, the quantile function may be used to construct a random variable having $\mathrm{F}$ as its distributions function. Generally speaking, the quantile function of a probability distribution has the following definition.

Assuming a random variable $X$ has a continuous and strictly monotonic distribution function $F(X)$. Then the quantile function of $X$ is the generalized inverse

$$
F^{-1}(\tau)=\inf \{x: F(x) \geq \tau\}
$$

where $\tau \in(0,1)$.

Thus the quantile function can be seen as the generalized inverse function of distribution function.

\subsection{Class I distribution}

The following two distribution classes are 
constructed by Jiang (2000) with using the idea of quantile modeling. Here we follow the terminology and notations used by him. That is, we use $Q_{I}(\alpha, \beta, \delta, \mu)$ to denote the Class I distribution whose quantile function is given below

$$
q_{I}(y ; \alpha, \beta, \delta, \mu)=\delta^{\frac{1}{\alpha}}\left\{\log \frac{y^{\beta}}{1-y^{\beta}}\right\}^{\left(\frac{1}{\alpha}\right)}+\mu
$$

where model parameters $\alpha, \beta, \delta \in R_{+} \quad$ and $\mu \in R$. The superscript ' $(\alpha)^{\prime}$ for $\alpha>0$ represents the operation below

$$
x^{(\alpha)}= \begin{cases}x^{\alpha} & \text { if } x>0 \\ 0 & \text { if } x=0 \\ -(-x)^{\alpha} & \text { if } x<0\end{cases}
$$

Remark: All parameters in (1) have intuitive interpretations: $\mu$ is a location parameter; $\delta$ functions as a scaling parameter; $\beta$ acts like a tail balance adjuster: $\beta=1$ means a balanced tail, and $\beta<(>) 1$ means the right (left) tail is fatter than the left (right) tail; and $\alpha$ indicates the tail order - the smaller the $\alpha$ is, the fatter the tail of the distribution is.

The cumulative distribution function and the probability density function (PDF) of $Q_{I}(\alpha, \beta, \delta, \mu)$ are also in closed-form. Particularly, the PDF is given by:

$$
p(x ; \alpha, \beta, \delta, \mu)=\frac{\alpha \cdot \frac{(x-\mu)^{(\alpha)}}{(x-\mu)} e^{-\frac{1}{\delta}(x-\mu)^{(\alpha)}}}{\delta \beta \cdot\left(1+e^{-\frac{1}{\delta}(x-\mu)^{(\alpha)}}\right)^{1+\frac{1}{\beta}}}
$$

for $x \in(-\infty, \mu) \cup(\mu,+\infty)$. We note that since a Class I distribution has closed-form probability density, a straightforward maximum likelihood estimation procedure can be employed to obtain the estimators of $\alpha, \beta, \delta$ and $\mu$.

\subsection{Class II distribution}

The Class II distribution is denoted by $Q_{I I}\left(\alpha_{-}, \alpha_{+}, \delta_{-}, \delta_{+}, \mu\right)$. It is constructed to fit the extremely unbalanced tails of empirical data. Its quantile function is specified as:

$$
q_{I I}\left(y ; \alpha_{-}, \alpha_{+}, \delta_{-}, \delta_{+}, \mu\right)=-\delta_{-}^{\frac{1}{\alpha_{-}}}\left(\log \frac{1}{y}\right)^{\frac{1}{\alpha_{+}}}+\delta_{+}^{\frac{1}{\alpha_{+}}}\left(\log \frac{1}{1-y}\right)^{\frac{1}{\alpha_{+}}}+\mu
$$

where model parameters $\alpha_{-}, \alpha_{+}, \delta_{-}, \delta_{+} \in R_{+}$and $\mu \in R$. We are mainly interested in the cases where $\alpha_{-} \leq 1, \alpha_{+} \leq 1$. Similar to a Class I distribution, $\alpha_{-}$and $\alpha_{+}$measure the fatness of tails of a Class II distribution.

\section{Quantile-GARCH Models}

\subsection{Quantile-based GARCH model}

Let $\left\{X_{t}, t \in Z\right\}$ be a stationary stochastic process adapted to the filtration $\left\{F_{t}, t \in Z\right\}$ with $F_{t}=\sigma\left(\left\{X_{s} ; s \leq t\right\}\right) . X_{t}$ is defined as:

$$
\begin{aligned}
& X_{t}=\sigma_{t} Z_{t} \\
& \sigma_{t}=f\left(X_{t-1}, \sigma_{t-1}^{2}\right)
\end{aligned}
$$

where $\left\{Z_{t}, t \in Z\right\}$ is a series of independent identical distribution in the form of Class I or Class II; $Z_{t}$ is assumed to be independent of $\left\{X_{t}, s \leq t\right\}$ and $f: R \times R_{+} \rightarrow R_{+}$is a strictly positive valued function. Jang and Deng called (4) as the Class I/II Guantile GARCH model.

$$
\text { If } f \text { takes the below form, then (4) becomes }
$$
the well known GARCH $(1,1)$ model.

$$
\begin{aligned}
& f\left(x, \sigma^{2}\right)=\alpha_{0}+\alpha_{1} x^{2}+\beta_{1} \sigma^{2}, \\
& \alpha_{0}, \alpha_{1}, \beta_{1}>0
\end{aligned}
$$

The classical GARCH model provides the Class I/II Quantile GARCH model (4) with certain inherent ability in capturing the volatility clustering of empirical data. Nevertheless, the most distinctive advantages of model (4) are its versatility and the easy to simulate feature, which stem from the closed conditional error distribution (Class I/II).

\subsection{VaR measure}

Following notations defined in section 3.1, we plan to apply quantile GARCH model to risk management. Specially, we shall demonstrate how the quantile GARCH model is ideally suited for Value-at-Risk (VaR) estimation for financial risk measurement. In the financial world nowadays, VaR( Value-at-Risk) has become one of the most important and frequently used measure for risk.

Let random variable $X$ represents the return 


\section{Risk Analysis and Crisis Response in Big Data Era (RAC-16)}

of a portfolio. The VaR of portfolio $X$ with confident level $\alpha(0<\alpha<1)$, denoted by $\operatorname{VaR}_{\alpha}(X)$, is a quantity that equals the worst loss to be expected of the portfolio $X$ over a given time horizon.

Formally,

$$
\begin{gathered}
x_{\alpha}(X)=\inf \{z \in R, P[X \leq x] \geq \alpha\} \\
\operatorname{VaR}_{\alpha}(X)=-x_{\alpha}(X)
\end{gathered}
$$

Note that

$$
\operatorname{VaR}_{\alpha}(X)=-q(\alpha)
$$

where $q(u)$ is the quantile function of $X$.

It is clear from equation (6) that the important risk management measures, VaR, can be obtained when the return models have closed form quantile functions. The Quantile GARCH model (4) is such an example. In fact, if a random variable $Z \sim Q_{I}(\alpha, \beta, \delta, \mu)$, then for any $\sigma>0$,

$$
\sigma Z \sim Q_{I}\left(\alpha, \beta, \sigma^{\alpha} \delta, \mu\right)
$$

Thus, if $Z_{t} \sim Q_{I}(\alpha, \beta, \delta, \mu)$ in (4), then

$$
X_{t} \mid F_{t-1} \sim Q_{I}\left(\alpha, \beta, \sigma^{\alpha} \delta, \mu\right)
$$

and its quantile function is in closed form. Same result holds true for $Z_{t} \sim Q_{I I}\left(\alpha_{-}, \alpha_{+}, \delta_{-}, \delta_{+}, \mu\right)$.

\section{Risk measure for Gold Spot}

The quantile GARCH model has been successfully applied in fitting Germany stock prices time series (see [5]). It is interesting to check if it also works well for the Chinese gold spot market, which is rather different from the other stock markets.

\subsection{Sample selection and Statistical Analysis}

The stock data used in this paper is AU9999 daily closing price, running from March 2, 2009 to February 29, 2016, with totally 1701 trading time's points. All of the data came from the RESSET financial database. The yield $r$ is defined as the log-return, namely $r_{i}=\log P_{i}-\log P_{i-1}$, where $P_{i} \quad$ is the daily closing price. Figure1 and Figure 2 show the AU9999 daily closing price and log-return of gold spot respectively.

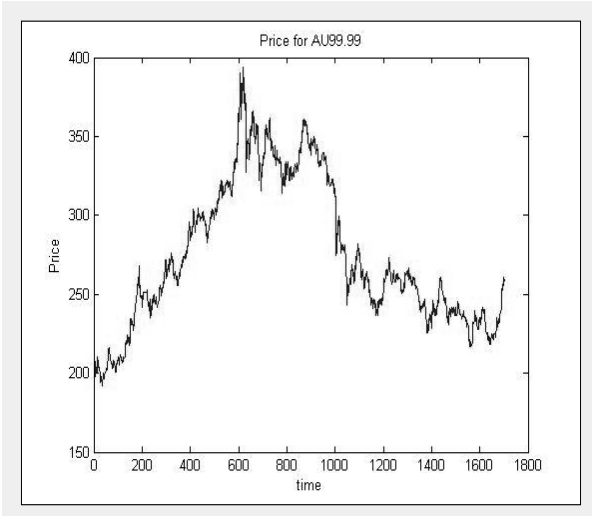

Figure 1. AU9999 daily closing price

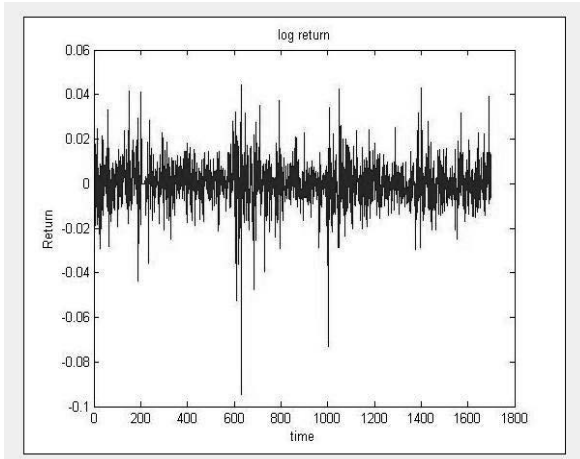

Figure 2. Log-Return of AU9999 price

To obtain the statistical features of gold spot time series, we input the data into statistical software Eviews8.0. Table 1 shows details statistical features of log-return

Adopting Ljung-Box $Q$ statistic to test self-correlation of the return series $r$, we find that the series is obvious self-correlation, therefore AR process could be used to fit yield series and we choose AR(3) finally.

Moreover, we used ARCH-LM method to test residual error series of AR (3) model of gold spot. LM test statistic, which is 28.1608 $(\mathrm{p}=0.0000)$, testifies the existence of $\mathrm{ARCH}$ effect. 
Risk Analysis and Crisis Response in Big Data Era (RAC-16)

Table 1. Statistical features of log-return

\begin{tabular}{|c|c|c|c|c|c|c|}
\hline name & Mean & Std & Skewness & Kurtosis & J-B statistic & Probability \\
\hline Gold Spot & 0.000123 & 0.010342 & -0.665665 & 10.7018 & 4327.22 & 0.000000 \\
\hline
\end{tabular}
plots of the empirical quantiles of the gold spot distributions versus the theoretical quantiles of the estimated Class II distributions, where the theoretical quantiles are plotted on the $\mathrm{x}$ axis and

Form fitted results of Figure 3, we find that each of the two Q-Q plots forms a relatively straight line, which indicates a good fit between the empirical quantiles function and theoretical quantiles function.

Table 2. Estimated parameters of Class II distributions

\begin{tabular}{cccccc}
\hline name & $\alpha_{-}$ & $\alpha_{+}$ & $\delta_{-}$ & $\delta_{+}$ & $\mu$ \\
\hline $\begin{array}{c}\text { Gold } \\
\text { future }\end{array}$ & 0.87195 & 0.72895 & 0.0098263 & 0.0158865 & 0.00146193 \\
\hline
\end{tabular}

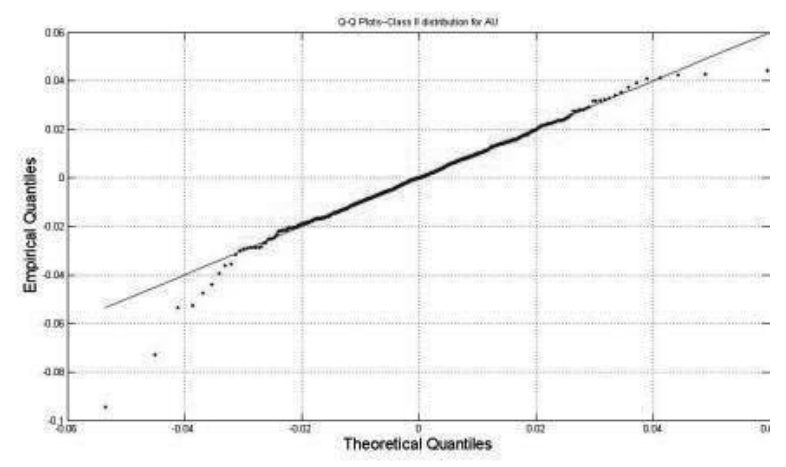

Figure 3. The Q-Q plots-Class II distributions for AU9999

ARCH-LM test shows there is at least 3-lag $\mathrm{ARCH}$ test, which means that the more parameters need to be estimated. Therefore, we adopt GARCH $(1,1)$ model to fit the volatility. We assume that standard residual error of following estimated model is subject to the Class II distribution.

In our empirical study, we employ a new parameter estimation method proposed by Jiang and Deng (2004), which consists of two main steps: the first step is to use the time series data to select a criteria function, either a quasi-likelihood function or a quasi-score function; and the second step is to search for a set of parameters such that the corresponding simulated data sample maximizes the criteria function chosen in the step one. They call it the efficient method of moment (EMM). The quantile GARCH model is very fast to simulate by design thus making EMM an effective method to apply.

Let AR(3) model be the mean equation of Quantile-GARCH(1,1). Using the EMM estimation method, we obtain the following model:

$$
\begin{gathered}
r_{t}=0.2095 r_{t-1}-0.0164 r_{t-2}+0.0645 r_{t-3} \\
\sigma_{t}^{2}=0.0002+0.0856 \varepsilon_{t-1}^{2}+0.8566 \sigma_{t-1}^{2}
\end{gathered}
$$

\subsection{Calculation of VaR}

It is clear that from equation (6) that $\mathrm{VaR}$ can be directly obtained if log-return of financial assets having a quantile function. In fact, the 
Risk Analysis and Crisis Response in Big Data Era (RAC-16)

Quantile-GARCH model is such an example. Adopting equation (6), we get the estimation value of VaR at confidence level $99 \%$ as the result in Table 3.

\begin{tabular}{cc}
\multicolumn{2}{c}{ Table 3. VaR estimations for Gold Spot } \\
\hline name & $V^{2} R_{0.99}$ \\
\hline Gold Spot & 0.0272
\end{tabular}

\section{Conclusion}

Accurately grasp the gold price volatility is very important for risk managers. Quantile-GARCH model is a new probability model for financial time series. In this article, we first reviewed the several quantile function proposed by Jiang and Deng and demonstrated the Quantile GARCH model's advantages. Using the EMM estimation method, we obtained a Quantile GARCH model which can fit $\log$ return series of China's Shanghai Gold Exchange Spot Gold Au9999. Finally, we calculated the VaR estimation values which should be directly applied in financial risk management.

\section{Acknowledgements}

This study was supported by 2016 year Yunnan Philosophy and Social Science Planning Project (YB2016016), Scientific Research Foundation of Yunnan Provincial Education Department and
Doctor Research Foundation of Yunnan Normal University.

\section{致谢}

本研究得到了本文受 2016 年度云南省哲学社 会科学规划项目（YB2016016）、云南省教育 厅科学研究基金资助性项目和云南师范大学 博士科研启动项目的资助。

\section{References}

[1] T. Bollerslev. Generalized autoregressive conditional heteroscedasticity. Journal of Econometrics, 31(3):307-327,1986.

[2] S. Laurent, P.G. Peterstj. Anoxpackage for estimating and fore casting various $\mathrm{ARCH}$ models . Journal of Economic Surveys, 16(3):447-485,2002.

[3] L. Falát, D. Marček. Volatility forecasting in financial risk management with statistical models and ARCH-RBF neural networks. Journal of Risk Analysis and Crisis Response, 4(2): 77-95, 2014.

[4] W.J. Jiang, S.J. Deng. Quantile-Based probabilistic models in electricity price modeling. Wiley Finance, 119-138,2004.

[5] W.J. Jiang. Some simulation-based models towards mathematical finance. Ph.D. Dissertation, University of Aarhus, 2000. 